\title{
Solar Powered Unmanned Cleaning Robot
}

\author{
Ravikumar P., Abirami K, Anushiya R., Elakkiya M., Harshidha P. R.
}

\begin{abstract}
Today, households are becoming smarter and automated. Soon, the non-renewable sources that are used today are going to get exhausted. So, the usage of renewable source of energy is very important. The aim of this project is to develop solar powered unmanned cleaning robot (SPUCR) without human guidance. The developed SPUCR is equipped with dry cleaning technology and controlled by Arduino mega microcontroller. The SPUCR navigates in all direction with the help of motors connected to the wheel. Obstacle sensor is used to detect the obstacles and helps the SPUCR in self-navigation. The LDR fixed with solar panel is used for sensing the solar light and convert it to battery voltage. The status of the battery is displayed using LCD. The IR sensor detects the Vacuum Cleaner status and sends the message via GSM. The location of SPUCR can be found using GPS. All the data are sent to the cloud with the help of WI-FI module. The technology is developed, and usage of smart phone has become wider. So, the navigation, location, battery level and light intensity of the Solar Powered Unmanned Cleaning Robot (SPUCR) can be monitored using the data stored in the cloud and displayed in android app application. The developed project is useful for dry cleaning by the residents and workers. The robot moves by itself without continuous human guidance and cleans the house or office. Thus, saving a lot of time and making it convenient and useful.
\end{abstract}

Keywords: Automation, SPUCR, Vacuum, Renewable, Cleaning Robot, location, android application.

\section{INTRODUCTION}

Robots are more commonly and widely used in many fields such as manufacturing, assembly and packing, transport, laboratory research, mass production of consumer and industrial goods ,etc., Robots are used to carry out many tasks that people are not interested to do because the jobs are boring, dirty or dangerous. One of the important household chores is floor cleaning which is often considered as difficult, unpleasant and boring job. Household residents hire the cleaners to do cleaning task. The hired cleaners may cause discomfort which led to the introduction of vacuum cleaner robot.Compact and efficient vacuum cleaner robot was developed for potential office and home use. They are very easy to use and consumes low power. It saves time and energy of humans. Vacuum cleaner robot cleans the home or office even in the absence of humans. Vacuum cleaner robot cleans minute dust particles which cannot be noticed by humans. The conventional vacuum cleaner system consists of large electrical and mechanical parts which are more expensive. It uses AC power consumption. This led to the invention of small vacuum cleaner robot. The small vacuum cleaner robot uses DC power and is of less cost.

Revised Manuscript Received on May 25, 2020.

* Correspondence Author

Ravikumar P*., Assistant Professor (Sr. G), KPRIET College, Coimbatore, India.

Abirami K., Department of EEE, KPRIET College, Coimbatore, India.

Anushiya R., Department of EEE, KPRIET College, Coimbatore, India.

Elakkiya M., Department of EEE, KPRIET College, Coimbatore, India.

Harshidha P. R., Department of EEE, KPRIET College, Coimbatore, India

(C) The Authors. Published by Blue Eyes Intelligence Engineering and Sciences Publication (BEIESP). This is an open access article under the CC BY-NC-ND license (http://creativecommons.org/licenses/by-nc-nd/4.0/)
Renewable source of energy can be used for vacuum cleaner robot. Renewable source of energy is cheap and pollution free. It is a source of energy which can be used repeatedly. It can also be naturally replaced with exhaustible energy resources. Renewable sources of energy include Wind energy, Tidal energy, Geothermal energy, Solar energy, Biomass, Biogas, Hydropower etc. Solar energy is used for vacuum cleaner robots. The developed solar powered unmanned cleaning robot (SPUCR) is equipped with dry cleaning technology which helps to reduce the work of cleaners. The robot operates for a given specific time to clean the room. The light intensity is focused, and the solar panel charges the battery. The robot moves to different direction and in case of obstacle detection, changes the direction.

\section{RELATED WORK}

\section{A. Design on Measurement and Control System of} Cleaning Robot Based on Sensor Array detection

A new quite home intelligent cleaner adopted the inaudible and infrared device array, that has performed the period surroundings perception, is introduced, and this cleaner driven by step-motor has the facility of autonomous operating by itself and thus the functions of the automatic obstacle detection and obstacle shunning. This paper adopts the grid scanning formula supported electrical map notice floor coverage task, and styles synthesis detection system supported device array finding technique technology per formula characteristics, experimental results for obstacle detection by static finding indicate that the designed detection system improves cleansing robot's surroundings perception and path search ability greatly.

\section{B. Deployment of mobile robots with energy and timing constraints}

Mobile robots are commonly used in many applications, like carpet cleaning, search and rescue operation, and exploration. Many studies are dedicated to the management, sensing, and communication of robots. However, the activity of robots has not been fully addressed. This paper investigates mechanism activity for coverage tasks. Every temporal property and energy constraints are considered; the robots carry restricted energy and wish to complete the tasks before deadlines. A speed-management technique is projected to form an alternative the traveling speeds to maximize the traveling distance beneath every energy and temporal property constraints.

\section{Solar tracker robot using microcontroller}

The target of this project is to develop an automatic star huntsman mechanism (STR) that is capable to trace most intensity level. The potency of the solar power conversion is often optimized by receiving most lightweight on the solar array.

Published By:

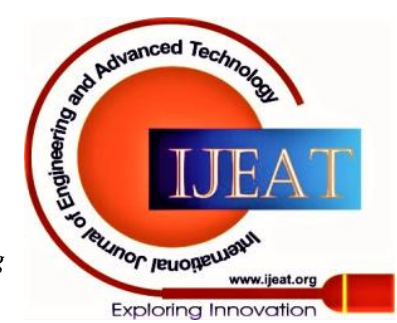


This mechanism is programmed to find daylight by exploitation two light-weights Dependent Resistors (LDR). Servo motor aligns the solar array to receive most lightweight. Digital compass is employed to find the position of the mechanism. Two changed DC servo motors can move the mechanism back to the initial position once the mechanism is out of position.

\section{PARAMETERS TO BE MEASURED}

The parameters focused in this project are Voltage, Dust detection, Light, Distance, Obstacle detection.

\section{A. Voltage}

The Voltage level in the battery can be measured using Voltage sensor. It is very much important to check the voltage level of the battery. It can measure AC level and/or DC level. The input to the voltage sensor is that the voltage itself and therefore the output are often analog voltage signals. The used type of the voltage sensor is resistive type voltage sensor. In the resistive network two resistors connected in series.

$$
\text { Vout }=(\mathrm{R} 2 /(\mathrm{R} 1+\mathrm{R} 2)) * \text { Vin }
$$

The midpoint of branch is taken to measurement as an analog input to Arduino.

\section{B. Light}

The intensity of sunshine may be detected using LDR (Light dependent resister) module. They supply massive amendment in resistance for changes in light level. The resistance of the photoresistor decreases with increase in incident candlepower. It's capable of trailing the sunshine and makes the automaton to maneuver towards the direction of the sunshine. Within the dark, a photoresistor have resistance in higher many mega ohms, whereas, within the light it has few hundred ohms.

\section{Obstacle detection}

Many types of sensors are used in robots to avoid collision, such as bump sensors, infrared sensors, laser range sensor and ultrasonic sensor. The obstacle can be detected using Ultrasonic sensor. When it detects the object nearby to $30 \mathrm{~cm}$, the robot can automatically change its direction either left or right with the help of servo motor. This helps to avoid collision with walls, or any other object.

\section{Distance}

The Proximity sensor is used to calculate the distance covered by the robot. The sensor is used to detect only the metal part of the robot for calculations. A part of metal is fixed to the wheel of mobile robot. If the lid is in contact with the sensor, it starts to calculate the distance. When the lid is rotated for 5 times, its $1 \mathrm{~m}$.

\section{E. Dust detection}

The dust can be collected in the vacuum cleaner. The IR (Infrared) sensor is fixed with the vacuum cleaner to detect if the vacuum cleaner is filled or empty. The IR sensor detects the dust $5 \mathrm{~cm}$ distance from its position. If the dust is filled in the vacuum cleaner, the command is passed to the respected person.

\section{WORKING}

The solar power unmanned cleaning robot comprises of different sensors (Voltage sensor, LDR, Proximity sensor, IR sensor, Ultrasonic sensor), Arduino AT Mega, Wi-Fi module, RTC, GSM, GPS, Servo motor, DC Gear motor, LCD, Battery, Solar panel, relay and Driver as illustrated in the block diagram in figure 1

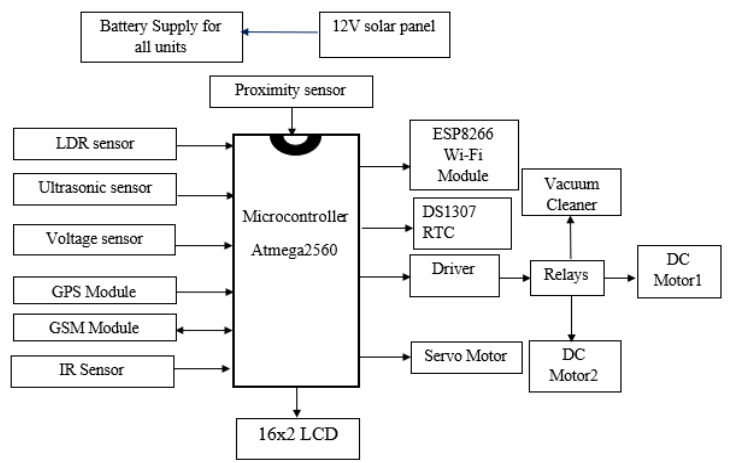

Fig.1: Block Diagram

The Arduino is the main component of the project as it controls the robot. The Battery supply is given as $12 \mathrm{v}$ and $5 \mathrm{v}$ to all the components. The voltage is sensed by voltage sensor and it is automatically updated to the LCD display and android app via Wi-Fi module. If the voltage is sensed as low, the LDR senses or search the light and charges the battery with the help of solar panel under the control of Arduino. The robot moves directly, when it senses the obstacle in front, then it can move to the possible left or right direction. The hardware without solar panel is shown in figure 2

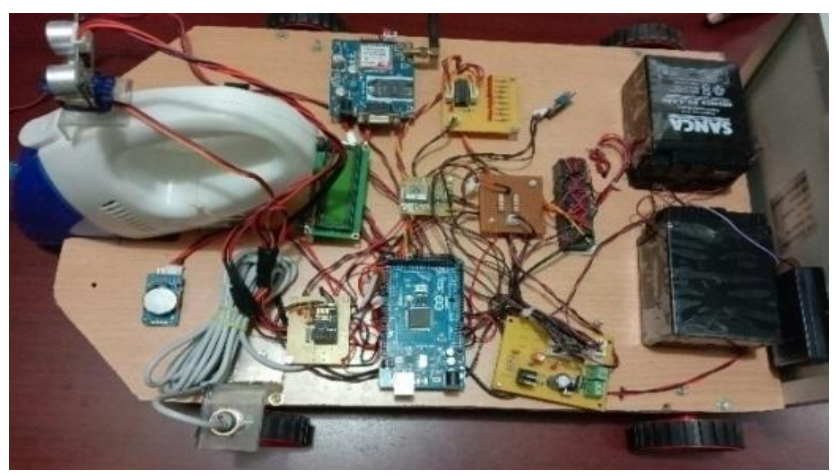

Fig. 2: Hardware without Solar panel

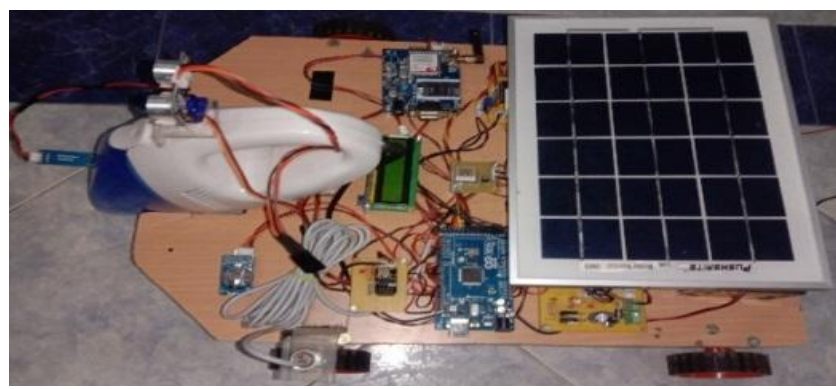

Fig. 3: Hardware with Solar panel

The hardware with solar panel is shown in figure 3 . The GSM and Arduino relate to UART connection. The location of the robot can be viewed by a person using GPS. The GSM can send the message when the dust bin is filled, and also when the voltage goes down as shown in figure 4 .

Published By:

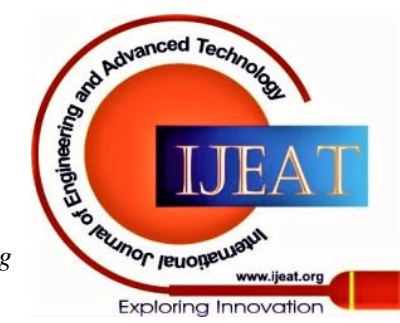

Blue Eyes Intelligence Engineering and Sciences Publication (C) Copyright: All rights reserved. 


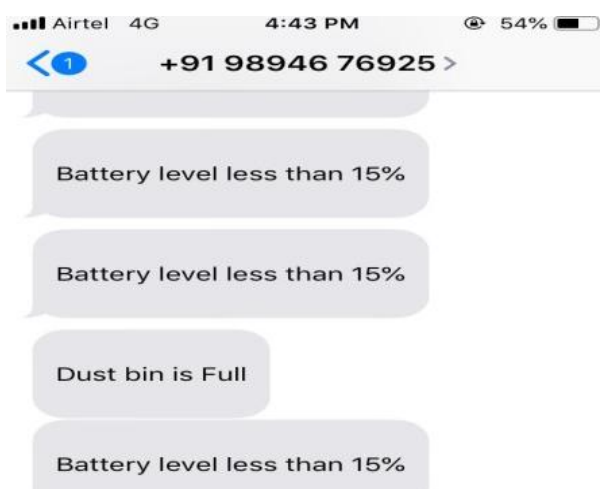

Fig. 4: Message indication

\section{RESULTS AND DISCUSSION}

The app is developed for supervising the robot. The parameters measured are stored in the cloud and taken whenever needed. The current distance, location (latitude and longitude), voltage, Light intensity can be viewed in the android app as shown in figure 5.

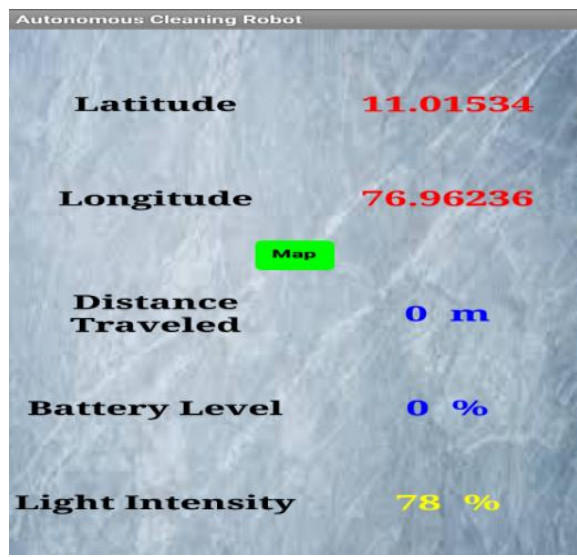

Fig. 5: Android app output

The location of the robot can be viewed using map in the android app as shown in figure 6. Hence, cleaning work is easy without manual work

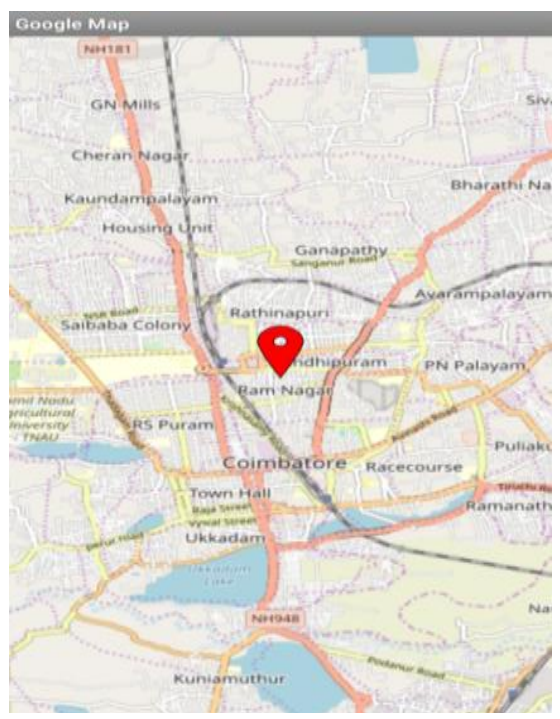

Fig. 6: GPS location

\section{CONCLUSION AND FUTURESCOPE}

This project shows that a traditional or conventional cleaning robot can be designed and integrated with networks and smart phones. In addition to the house cleaning task, autonomous tracking, remote monitoring, and controlling through internet and Wi-Fi was also possible. Remote monitoring helps to track the location of the robot and avoid theft. Hence helps to reduce the human work and provide comfort to humans. In order to let the Solar panel to perform in all weather conditions, the Solar panel must be designed to become waterproof so, it will not face any downside throughout period. This can want more effort on mechanical style of the Unmanned cleaning robot.

\section{REFERENCES}

1. M. Kang, K. Kim, D. Noh, J. Han and S. Ko (2014) 'A robust obstacle detection method for robotic vacuum cleaners', IEEE Transactions on Consumer Electronics, Vol.60, No.4.

2. Z. Zhao, W. Chen, C. C. Y. Peter and X. Wu (2016) 'A novel navigation system for indoor cleaning robot', IEEE International Conference on Robotics and Biometics (ROBIO), Qingdao, pp. 21592164.

3. Chih-Hao Chen and Kai-Tai Song (2005) 'Complete coverage motion control of a cleaning robot using infrared sensors', IEEE International Conference on Mechatronics, pp. 543-548.

4. Vatsal N Shah, Sathvik K , Asst. Prof. Abhishek Vaghela (2016) 'Floor Cleaning Robot', IJERT, Vol.4, No.10.

5. S. J. Shanmugavel, L. Siva Balaji, P. Siva Sankar, K. Subash, K. Gowthami (2020) 'Automatic Table Cleaning Robot', IJITEE, Vol.9, No.5.

6. P. S. Kwek, Z. W. Siew, C. H. Wong, B. L. Chua and K. T. Kin Teo (2012) 'Development of a wireless device control based mobile robot navigation system', IEEE Global High Tech Congress on Electronics, Shenzhen, pp.95-100.

7. J. Palacin, J. A. Salse, I. Valganon and X. Clua (2004) 'Building a mobile robot for a floor-cleaning operation in domestic environments', IEEE Transactions on Instrumentation and Measurement, Vol.53, No.5, pp.1418-1424.

8. Kuldeep Soni (2017) 'Autonomous Smart Floor Cleaning Robot', IJERT, Vol.5, No.23.

9. Yongguo Mei, Yung-Hsiang Lu, Y. C. Hu and C. S. G. Lee (2006) 'Deployment of mobile robots with energy and timing constraints', IEEE Transactions on Robotics, Vol.22, No.3, pp.507522.

10. Sivasankar, B. Durgalakshmi, K. Seyatha (2017) 'Autonomous Trash Collecting Robot', IJERT, Vol.6, No.4

\section{AUTHORS PROFILE}

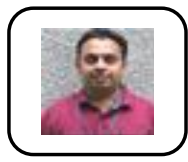

Mr. Ravikumar P. received his Bachelor's Degree in Electrical and Electronics Engineering from Anna University, Chennai, 2009. Master's Degree in Electrical Drives and Embedded Control from Anna University of Technology in 2011. He is pursuing his Ph.D in the area of Power Electronics from Anna University, Chennai. He has six years of teaching experience. He has published 4 papers in international journals, 2 in international conferences and 4 in national conferences. He also handles workshop on Matlab,labView, MagNet and ElecNet. His research interests are in Electromagnetic interference, multiport converter configurations and battery powered electric vehicles.

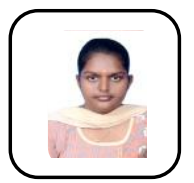

Abirami K. final year student pursuing bachelor's degree in Electrical and Electronics Engineering at KPR Institute of Engineering and Technology, Coimbatore, India.

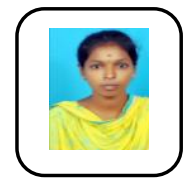

Anushiya R. final year student pursuing bachelor's degree in Electrical and Electronics Engineering at KPR Institute of Engineering and Technology, Coimbatore, India.

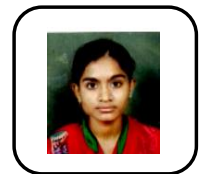

Elakkiya M. final year student pursuing bachelor's degree in Electrical and Electronics Engineering at KPR Institute of Engineering and Technology, Coimbatore, India.

Published By:

Blue Eyes Intelligence Engineering

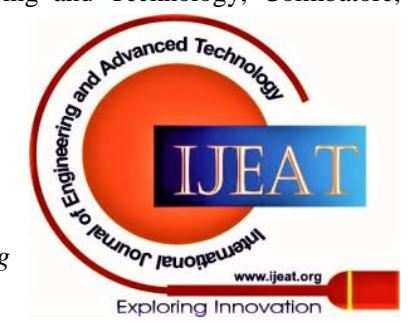




\section{Solar Powered Unmanned Cleaning Robot}

Harshidha P.R. final year student pursuing bachelor's

degree in Electrical and Electronics Engineering at KPR

Institute of Engineering and Technology, Coimbatore,

India. 